\title{
Impact of Information Literacy Skill on Students' Academic Performance in Bangladesh
}

\author{
Purnima Banik ${ }^{1}$, Bezon Kumar ${ }^{2, *}$ \\ ${ }^{1}$ Department of Information Science and Library Management, Rajshahi University, Rajshahi, Bangladesh \\ ${ }^{2}$ Department of Economics, Varendra University, Rajshahi, Bangladesh
}

Email address:

banik.ru10@gmail.com (P. Banik), bezon.kumar3@gmail.com (B. Kumar)

${ }^{*}$ Corresponding author

To cite this article:

Purnima Banik, Bezon Kumar. Impact of Information Literacy Skill on Students' Academic Performance in Bangladesh. International Journal of European Studies. Vol. 3, No. 1, 2019, pp. 27-33. doi: 10.11648/j.ijes.20190301.15

Received: March 5, 2019; Accepted: April 9, 2019; Published: May 6, 2019

\begin{abstract}
The study explores the level of academic performance and information literacy skill of undergraduate students in Bangladesh. In addition, the study examines the impact of information literacy skill on students' academic performance. To achieve the objectives, the study uses primary data collected from 325 students and employs several statistical and econometric methods. The study firstly uses information literacy skill index to measure the level of students' information literacy skill and secondly, uses a linear regression estimated by OLS method to examine the impact of information literacy skill on students' academic performance. The study finds that most of the students' Grade Point Average (GPA) is medium standard which ranges between 3.01 and 3.50 and the level of information literacy skill is lower which ranges between 10 and 20 . Besides, the study also finds that study hour, family income, class attendance, past academic result and information literacy skill are the significant factors which influence students' academic performance. More specifically, the study finds that students' GPA may be increased by 0.012 if students' information literacy skill is increased by one unit. Therefore, the study suggests nursing students' information literacy skill to improve the students' academic performance.
\end{abstract}

Keywords: Academic Performance, Information Literacy Skill, Bangladesh

\section{Introduction}

To develop a nation, there is no alternative to quality education. University is the institution which provides quality higher education to the nation and higher education is one of the most important tools for research productivity. One hundred and forty-five numbers of universities (both private and public) are playing their role in promoting higher education in Bangladesh [1]. Every year a large number of students are being enrolled in different disciplines in these universities and, they are the important assets and main power of the nation. Their earned skills from academic background can develop the economy of a country as the socio-economic development of a country is directly linked with students' academic performance. Students' academic performance plays a vital role in producing the best quality graduates who will become the great leader and manpower for the country in future and contribute to the country's socio-economic development [2-3]. Therefore, students' academic performance measurement has received considerable attention to the researchers.

Students' academic performance is affected by many factors like social, economic, psychological, environmental and personal factors [2]. Although these factors strongly influence students' academic performance, these factors vary from person to person and place to place. Previous studies highlights on different factors like class schedules, class size, the environment of the class, the technology used in the class and exams systems, guidance, English textbooks, homework, extracurricular activities, family income and so on. Contrarily, the present study is different in a way that it is the first research in which a variable "students" information literacy skill" is studied. Broadly speaking, the core contribution of this study is that it explores the impact of information literacy skill on students' academic performance. This paper may be helpful for the parents and teachers of the students and, policymakers to design and implement the 
policies to improve the students' performance and the quality of education by improving students' information literacy skill.

\section{Literature Review}

Students' academic performance means the extent to which a student academically achieved the educational goals. Most of the researchers in previous studies have measured the academic performance by GPA in a particular year or semester [3-9]. GPA of a student depends on many factors. Information literacy skill is one of them.

Generally, literacy means the ability of a person to read and write. There are different types of literacy such as visual literacy, computer literacy, media literacy, technical literacy, information literacy and so on. Nowadays, the importance of information literacy is increasing significantly. Information literacy means the ability to know the need for information and the ability to identify, locate, evaluate, and effectively use of information for solving a problem practically. "To be information literate, a person must be able to recognize when information is needed and have the ability to locate, evaluate and use effectively the needed information" is stated by The American Library Association (ALA) [10]. Although different researchers have measured information literacy skill in different ways, most of the researchers have measured it using index [11-14].

Variables affecting students' academic performance can be grouped into three categories of variables broadly such as: (i) idiosyncratic variables, (ii) socio-economic variables, and (iii) institutional variables [8]. All these three categories of variables include many factors that influence students' academic performances are shown in Figure 1.

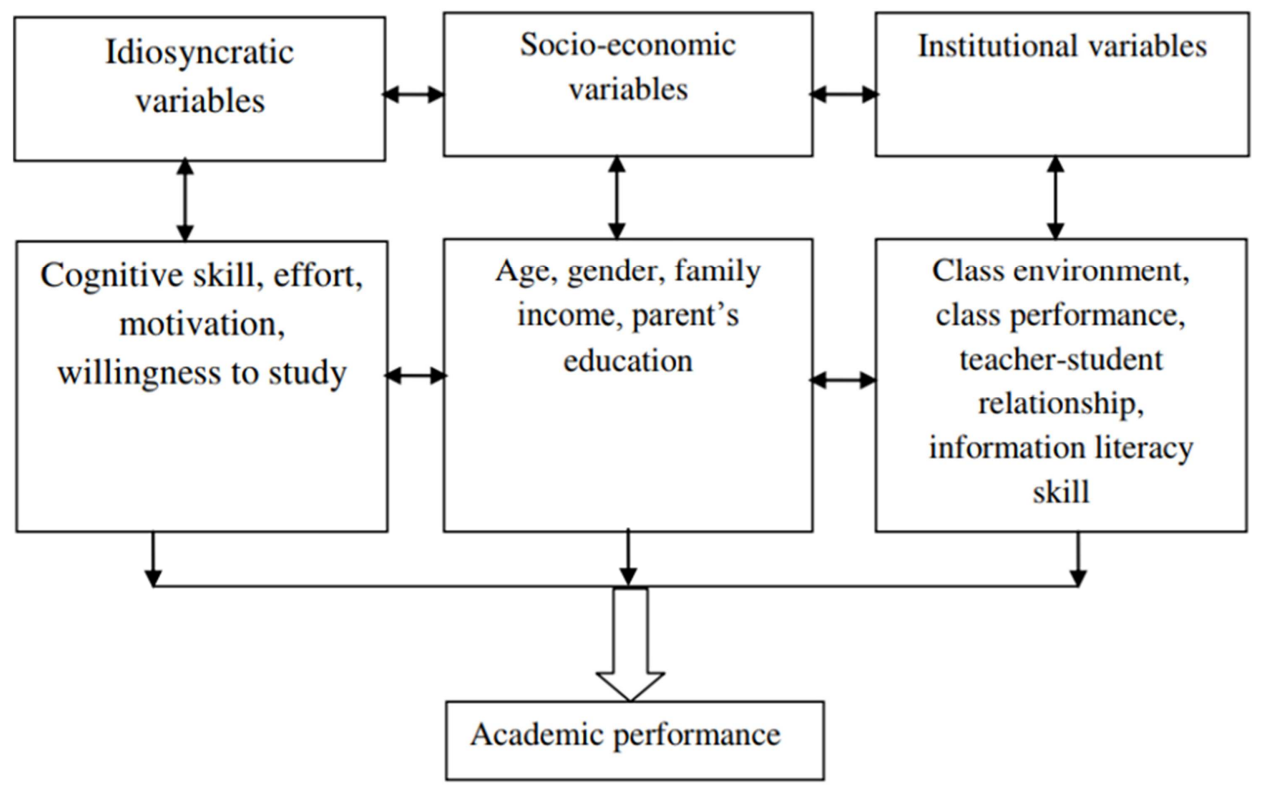

Source: Adapted from Rosi, 2017

Figure 1. Factors Affecting Academic Performance.

Previous studies show that there are many factors which affect the academic performance of the students in Bangladesh. According to Ahmmad and Salim, variables like gender, class attendance, type of department, teacher-student relationship, the result of pre-university public examinations, self-confidence level of the students, depression and amount of credit hours completed are the significant factors affecting students' academic performance [4]. Hossain et al. have found that the result of SSC and HSC examination are the reasonable factors influencing the academic performance [15]. Applying the logistic regression analysis, Shahiduzzaman et al. have found that sex, family type, faculty, students' monthly expenditure, the result of SSC, the result of HSC and semester dropped of the students were the important predictors for the academic performance of the students of private universities of Bangladesh [16]. On the other hand, Ahmad and Rahman have found that extracurricular activities have a strong influence on academic performance [5]. By applying correlation analysis, a study found that academic achievement of students has a considerable negative and significant relationship with all the attributes of problem behavior such as emotional symptoms, conduct problems, hyperactivity-inattention and, peer problems [17]. While Ahmed and Khanam revealed that academic achievement was significantly correlated with academic self-efficacy, organization, and meta-cognitive self - regulation [18], Alam et al. revealed that age, gender, past academic track, medium of education and absence in the classes have significant influence on the academic performances of a student [19].

Outside Bangladesh, a number of studies have been carried out on this issue. They have also found different factors like students' admission points, parents' socio-economic status and former school background that affect the academic performance of the students. Using Pearson Correlation Coefficient test, Danyial pointed out that parent's education, 
family income and participation in co-curricular activities are the significant factors affecting students' academic performance [20] while applying a linear regression Ali et al. revealed that age, father's social economic status and daily study hours significantly contribute to the academic performance of graduate students [3]. Besides, Fernando found that self-determination, time management, English knowledge and students' attendance on lectures are positively and significantly affecting the academic performance [7]. Applying regression analysis it was found that factors like students' attendance, mother's education and the presence of the trained teacher in the school have a positive impact on students' academic performance [23]. A study in India found that cognitive and non-cognitive factors affect Grade Point Averages of young adults [21] while utilizing correlation analysis, Rosi found that there is no such relationship in the case of evening students [8]. Hijazi and Naqvi have found that family income and study hour have negative, and attendance and mother's education have positive effects on academic performance [9]. Like the other factors, family size, the gender of students, and resident of students and income level of their parents are also responsible for students' performance [22].

Keeping in view the literature, this study is organized to assess the factors affecting the academic performance of the students in Bangladesh.

\section{Methodology}

\subsection{Sample Design and Data Collection}

The study is mainly based on primary data. For conducting the study, Rajshahi district of Bangladesh, known as education city, has been selected as the study area. There are four universities in Rajshahi district in which academic activities are running now. Among them, two are public universities such as Rajshahi University and Rajshahi University of Engineering and Technology and, others two are private universities such as Varendra University and North Bengal International University. From these four universities, one university is selected following simple random sampling method and the selected university is Varendra University. Varendra University had 12 academic departments where about 5000 students were studying. Following the simple random sampling method, a total of 350 questionnaires were distributed proportionately among the undergraduate students in different departments in September, 2018 and 335 questionnaires were got back. Among them, 10 questionnaires were not properly filled up, thus, they were rejected. Finally, after sorting, coding and editing 325 questionnaires are used for the analysis.

\subsection{Empirical Methods}

\subsubsection{Measurement of the Level of Academic Performance}

Although different researchers have measured students' academic performance in different ways, following previous studies the present study measures the level of students' academic performance by the last year examination's Grade Point Average (GPA) [3-9]. As the study is carried out in undergraduate level, students' GPA of a particular year is in the scale of 4.00. In this study, GPA 3.00 and below out of GPA 4.00 has been considered as the low standard performance while GPA 3.01 to 3.50 and GPA 3.51 to 4.00 have been considered as medium standard and the high standard performance.

\subsubsection{Measurement of the Level of Information Literacy Skill}

The present study has measured the level of students' information literacy skill with an index-"information literacy skill index" following previous studies [11-14]. This newly constructed index is the sum of five components having ten distinct indicators. These indicators are measured with five points likert scale such as strongly disagree $=1$, disagree $=2$, neither agree nor disagree $=3$, agree $=4$ and strongly agree $=$ 5. The estimated value of the information literacy skill index ranges from 10 to 50. In this study, the value ranges from 10 to 20 has been considered as the lower level of information literacy skill. On the other hand, 21 to 30 and 31 to 50 have been considered as average and the higher level of information literacy skill, respectively. The components and indicators of the information literacy skill index are shown in Table 1.

Table 1. Components and Indicators of Information Literacy Skill Index.

\begin{tabular}{|c|c|}
\hline Components & Indicators \\
\hline \multirow{2}{*}{ Identification } & Identifying the lack of knowledge in a subject area \\
\hline & Deciding what information is needed, and how much \\
\hline \multirow{2}{*}{ Searching } & Finding relevant information within books \\
\hline & Finding relevant information online \\
\hline Evaluation & $\begin{array}{l}\text { Evaluating information sources according to my } \\
\text { needs }\end{array}$ \\
\hline \multirow{4}{*}{ Application } & $\begin{array}{l}\text { Using online indexes, abstracts and full text journals } \\
\text { and books }\end{array}$ \\
\hline & Using Computer and Internet \\
\hline & Making bibliography or reference list \\
\hline & Making assignments and presentations \\
\hline Acknowledgement & $\begin{array}{l}\text { Understanding concepts of the fair use, copyright } \\
\text { and plagiarism }\end{array}$ \\
\hline
\end{tabular}

\subsubsection{Estimation of the Factors Affecting Academic Performance}

There are a lot of factors that affect the academic performance of university students. The present study has considered a cause and effect relationship between academic performance and a set of influencing factors which is shown in the following equation:

$$
P_{i}=f\left(X_{i}\right)
$$

Where, $\mathrm{P}_{\mathrm{i}}=$ academic performance and $\mathrm{X}_{\mathrm{i}}=$ a set of socioeconomic, demographic and institutional factors that affect academic performance. Academic performance in this study is measured by last year examination's Grade Point Average (GPA). Since the dependent variable is continuous, following earlier studies a linear regression estimated by OLS method is applied to find out the factors affecting students' academic 
performance $[8,9,19,24]$. The specified regression model is as follows.

$$
\begin{aligned}
& P_{i}=\beta_{0}+\beta_{1} X_{1}+\beta_{2} X_{2}+\beta_{3} X_{3} \\
& +\beta_{4} X_{4}+\beta_{5} X_{5}+\beta_{6} X_{6}+\beta_{7} X_{7}+\beta_{8} X_{8}+u_{i}
\end{aligned}
$$

Where, $P_{i}$ is academic performance; $\beta_{0} \ldots \ldots \beta_{8}$ are parameters to be estimated; $\mathrm{X}_{1}, \mathrm{X}_{2} \ldots \ldots . \mathrm{X}_{8}$ are the explanatory variables that affect academic performance and $\mathrm{u}_{\mathrm{i}}$ is the stochastic disturbance term. The regression equation (2) shows a linear relationship between the dependent variable with a set of eight explanatory variables. The equation (2) is estimated through a linear regression by the OLS method. The explanatory variables considered in equation (2) are described in Table 2.

\begin{tabular}{|c|c|c|c|}
\hline Name of Variables & Type & Measurement & Expected Sign \\
\hline Study hour $\left(\mathrm{X}_{1}\right)$ & Continuous & Averagely total hours of study per day & + \\
\hline Family income $\left(\mathrm{X}_{2}\right)$ & Continuous & Family's total income per month (Tk.) & + \\
\hline Parent's education $\left(\mathrm{X}_{3}\right)$ & Continuous & Average years of father's and mother's education & + \\
\hline Class attendance $\left(\mathrm{X}_{4}\right)$ & Dummy & 1 if good ( $90 \%$ and above attendance), otherwise 0 & + \\
\hline Class performance $\left(\mathrm{X}_{5}\right)$ & Dummy & 1 if good ( $80 \%$ and above marks), otherwise 0 & + \\
\hline Past academic result $\left(\mathrm{X}_{6}\right)$ & Continuous & Average of Secondary and Higher Secondary examination result (GPA) & + \\
\hline Secondary school location $\left(\mathrm{X}_{7}\right)$ & Dummy & 1 if urban, otherwise 0 & + \\
\hline Information literacy skill $\left(\mathrm{X}_{8}\right)$ & Continuous & Estimated value of information literacy skill index & + \\
\hline
\end{tabular}

Table 2. Description of Explanatory Variables Used in Regression Model.

\section{Results and Discussion}

\subsection{Socio-economic, Demographic and Institutional Features of Students}

The socio-economic, demographic and institutional features of students are analyzed through SPSS 23 and presented in tabular form in the following table.

Table 3. Socio-economic, Demographic and Institutional Features of

\begin{tabular}{|c|c|c|}
\hline Features & Categories & Percentage \\
\hline \multirow{4}{*}{ Age (years) } & 20 and below & 29 \\
\hline & 20.1 to 22 & 37 \\
\hline & 22.1 to 24 & 23 \\
\hline & 24 and above & 11 \\
\hline \multirow{2}{*}{ Sex } & Male & 57 \\
\hline & Female & 43 \\
\hline \multirow{4}{*}{ Study year } & First year & 27 \\
\hline & Second year & 33 \\
\hline & Third year & 23 \\
\hline & Fourth year & 17 \\
\hline \multirow{4}{*}{ Study faculty } & Arts and Social Science & 52 \\
\hline & Business & 21 \\
\hline & Biology & 9 \\
\hline & Engineering & 18 \\
\hline \multirow{4}{*}{ Study hour (hours/day) } & 2.00 and below & 61 \\
\hline & 2.01 to 4.00 & 28 \\
\hline & 4.01 to 6.00 & 7 \\
\hline & 6.01 and above & 4 \\
\hline \multirow{4}{*}{ Parents' education (years) } & No formal education & 9 \\
\hline & 0 to 5 & 29 \\
\hline & 6 to 10 & 37 \\
\hline & 11 to 16 & 25 \\
\hline \multirow{4}{*}{ Family income (Tk./month) } & 15000 and below & 33 \\
\hline & 15001 to 25000 & 42 \\
\hline & 25001 to 35000 & 16 \\
\hline & 35001 and above & 9 \\
\hline \multirow{3}{*}{$\begin{array}{l}\text { Class attendance (present in } \\
\text { class) }\end{array}$} & Lower ( $60 \%$ and below) & 23 \\
\hline & Average $(61 \%$ to $89 \%)$ & 49 \\
\hline & Excellent ( $90 \%$ and above) & 28 \\
\hline \multirow{3}{*}{$\begin{array}{l}\text { Class performance (got } \\
\text { marks in class) }\end{array}$} & Lower ( $50 \%$ and below) & 26 \\
\hline & Average $(51 \%$ to $79 \%)$ & 47 \\
\hline & Excellent ( $80 \%$ and above) & 27 \\
\hline
\end{tabular}
Students.

\begin{tabular}{lll}
\hline Features & Categories & Percentage \\
\hline \multirow{2}{*}{ Past academic result (GPA } & 3.50 and below & 33 \\
in the scale of 5.00) & 3.51 to 4.50 & 45 \\
\multirow{2}{*}{ Secondary school location } & 4.51 to 5.00 & 22 \\
& Rural & 57 \\
& Urban & 43 \\
\hline
\end{tabular}

Source: Field survey, 2018

The Table 3 shows that most of the students' age is between 20.1 and 22 years and they are male. On the other hand, it is found that the majority of the sampled students study in second year in Arts and Social Science faculty which is 33 percent and 52 percent, respectively. The study finds that 61 percent of students study 2.00 hours and below a day. Table 3 also shows that the level of education of the majority students' parent is between 6 to 10 years while their monthly family income is between Tk.15001 and Tk.25000. Most of the students attend in the class averagely (61\% to $89 \%)$ and their class performance (got marks in the class test, assignment, presentation, and group discussion) is also average $(51 \%$ to $79 \%)$. From the above analysis, it is also found that the past academic result of the majority students is between 3.51 and 4.50 in the scale of 5.00 and their secondary school location is in rural areas.

\subsection{Level of Academic Performance of Students}

The level of students' academic performance is measured by the last year's GPA. The result is analyzed through SPSS 23 and presented in tabular form in the following table.

Table 4. Level of Academic Performance of Students.

\begin{tabular}{lll}
\hline Level of performance (GPA) & Frequency & Percentage \\
\hline GPA 3.00 and below & 81 & 25 \\
GPA 3.01 to GPA 3.50 & 150 & 46 \\
GPA 3.51 to GPA 4.00 & 94 & 29 \\
Total & 325 & 100 \\
\hline
\end{tabular}

Source: Field survey, 2018

Table 4 shows that 25 percent of students obtained GPA 3.00 and below in the last year examination. On the other 
hand, maximum students (46 percent) achieved a medium standard GPA which ranges from GPA 3.01 to GPA 3.50 while 29 percent of students obtained the highest GPA i.e GPA 3.51 to GPA 4.00. From the above analysis, it is found that most of the students' GPA is the medium standard which is between GPA 3.01 and GPA 3.50.

\subsection{Level of Information Literacy Skill of Students}

The level of students' information literacy skill is measured with an index. The result is analyzed through SPSS 23 and presented in tabular form in the following table.

Table 5. Level of Information Literacy Skill of Students.

\begin{tabular}{lll}
\hline Level of information literacy skill & Frequency & Percentage \\
\hline Lower (10 to 20) & 137 & 42 \\
Average (21 to 30) & 117 & 36 \\
Higher (31 to 50) & 71 & 22 \\
Total & 325 & 100 \\
\hline
\end{tabular}

Source: Field survey, 2018

Table 5 shows that most of the students (42 percent) had a lower level of information literacy skill. On the other hand, 36 percent of students had an average level of information literacy skill while 22 percent of students had the higher level of information literacy skill. From the above analysis, it is found that most of the students' information literacy skill level was lower which is between 10 and 20 .

\subsection{Factors Affecting Students' Academic Performance}

The study examines the factors affecting students' academic performance with a linear regression estimated through OLS method. The result is analyzed through STATA 13 and presented in tabular form in the following table.

Table 6. Factors Affecting Students' Academic Performance.

\begin{tabular}{lllll}
\hline Variable & Coefficient & $\begin{array}{l}\text { Robust } \\
\text { Std. Err. }\end{array}$ & t-ratio & $\mathbf{p}>|\mathbf{t}|$ \\
\hline Constant*** & 1.898 & 0.204 & 9.28 & 0.00 \\
Study hour** & 0.011 & 0.005 & 2.21 & 0.03 \\
Family income* & 0.033 & 0.012 & 1.66 & 0.09 \\
Parent's education & 0.004 & 0.004 & 0.97 & 0.33 \\
Class attendance* & 0.055 & 0.030 & 1.82 & 0.07 \\
Class performance & 0.005 & 0.036 & 0.13 & 0.89 \\
Past academic result* & 0.017 & 0.009 & 1.81 & 0.07 \\
Secondary school location & 0.004 & 0.045 & 0.10 & 0.92 \\
Information literacy skill*** & 0.012 & 0.001 & 9.28 & 0.00 \\
\hline
\end{tabular}

$\mathrm{F}(8,316)=86.97 ;$ Prob. $>\mathrm{F}=0.0000 ; \mathrm{R} 2=0.9180 ;$ Root $\mathrm{MSE}=0.11019$; $\mathrm{DW}=1.97$

Note: $* * *, * *$ and $*$ means $1 \%, 5 \%$ and $10 \%$ level of significance

Source: Field survey, 2018

The table 6 shows that the value of $R^{2}$ is 0.9180 indicates that explanatory variables of the model explain the dependent variable by 92 percent. Elsewhere, the F-statistic value $(86.97$ with prob $>\mathrm{F}=0.000$ ) brings out that the model is completely good at fitted. The study had no heteroscedasticity problem in the data because it is clarified using robust standard error action. The study also exercised VIF to detect multicollinearity problem and the estimated VIF explicitly revealed was below
10 i.e. no multicollinearity. The Durbin Watson test $(\mathrm{DW}=$ 1.97) expresses that no autocorrelation problem exists in the model. The study finds that study hour, family income, class attendance, past academic result and information literacy skill are the significantly affect students' academic performance although all variables exhibited the expected sign.

The estimated coefficient of study hour is 0.011 exhibits that the students' GPA may be increased by 0.011 if the students' study hour is increased by one hour per day. This is significant at 5 percent level of significance. The dynamic explanation may be that the more the students will study, the more the students will gather skill and knowledge and improve GPA. This finding violates the finding of Hijazi and Naqvi [9] in such a way that Hijazi and Naqvi [9] found a negative direction between study hour and students' academic performance but the present study found a positive direction.

The coefficient of family income reveals that students' GPA may be increased by 0.033 if the students' monthly family income is increased by one unit which is significant at 10 percent level of significance. The rational explanation may be that students having the higher family income have the higher opportunities to spend on education purposes. This may help to gather more knowledge and improve academic performance. Although this finding is in line with Rosi [8], it contradicts with the finding of Hijazi and Naqvi [9].

The students' GPA may be increased by 0.055 if the students' class attendance is good which is significant at 10 percent level of significance. The interpretation may be that if a student attends in the class regularly, he or she may gather more knowledge which contributes to the improvement of students' academic performance. This result is in line with Ahmmad and Salim [4], Fernando [7], Hijazi and Naqvi [9] and Raychaudhuri et al [23].

Similarly, students' GPA may be increased by 0.017 if students' past academic result would be higher by one unit. This result is significant at 10 percent level of significance and can be interpreted by the fact that the students who have bright results in the past may give more effort in the study which may improve students' GPA. Similar result has been found by Ahmmad and Salim [4], Rosi [8], Hossain et al. [15], Shahiduzzaman et al. [16] and Alam et al. [19].

The study also shows that the students' GPA may be increased by 0.012 if the level of students' information literacy skill is increased by one which is significant at 1 percent level of significance. This finding can be interpreted by the fact that students who have the higher level of information literacy skill have the higher level of knowledge. This increasing level of knowledge may improve students' GPA.

\section{Conclusion and Policy Recommendation}

The study emanates two findings. First, the study finds that maximum students obtain GPA between 3.01 and 3.50 and the level of information literacy skill of maximum students is lower 
which ranges between 10 and 20. Second, the study finds that study hour, family income, class attendance, past academic result and information literacy skill are the significant factors which influence students' academic performance. In addition, the study finds that students' GPA may be increased by 0.012 if students' information literacy skill is increased by one. Therefore, the study suggests government and non-government organizations taking proper initiatives to develop students' information literacy skill. Students' information literacy skill may be developed by providing them proper quality education and training both in academic and vocational aspects; making them interested in identifying problems and, searching and applying information; making them efficient in using Computer and Internet and making them efficient in fair use and acknowledgement of information. With the developed information literacy skill, students' academic performance may be improved significantly and it may contribute to the national development.

\section{References}

[1] Bangladesh University Grant Commission Website. www.ugc.gov.bd.

[2] Mushtaq, I. and Khan, S. N. (2012). Factors affecting students' academic performance. Global Journal of Management and Business Research, 12 (9): 17-22. https://globaljournals.org/GJMBR_Volume12/3FactorsAffecting-Studentsacademic.pdf.

[3] Ali, S., Haider, Z., Munir, F., Khan, H. and Ahmed, A. (2013). Factors contributing to the students' academic performance: a case study of Islamia University Sub-Campus. American Journal of Educational Research, 1 (8): 283-289. 10.12691/education-1-8-3.

[4] Ahmmed, M. M. and Salim, Z. R. (2018). Determinants of academic performance of undergraduate students in private universities in Bangladesh: a case Study. Global Journal of Management and Business Research, 18 (11): 28-34. https://socialscienceresearch.org/index.php/GJHSS/article/vie w/2622/2511.

[5] Ahmad, M. and Rahman, M. F. (2019). Extracurricular activities and student's academic performance. Journal of Armed Forces Medical College, Bangladesh, 11 (2): 1-2. https://doi.org/10.3329/jafmc.v11i2.39814.

[6] Sikhwari, T. D., Mapgosa, C., Masehela, L. and Ndebele, C. (2017). Exploring students' views on factors affecting academic performance in a South African University. International Journal of Educational Sciences, 10 (3): 442450. https://doi.org/10.1080/09751122.2015.11890367.

[7] Fernando, R. L. S. (2017). Determinants of academic performance of undergraduates of the faculty of management studies and commerce of the University of Sri Jayewardenepura in Sri Lanka. International Journal of Social Sciences, $\quad 3 \quad$ (2): 1077-1101. https://dx.doi.org/10.20319/pijss.2017.32.10771101.

[8] Rosi, M. (2017). Factors affecting academic performance of university evening students. Journal of Education and Human Development, 6 (1): 96-102. 10.15640/jehd.v6n1a10.
[9] Hijazi, S. T. and Naqvi, S. M. M. R. (2006). Factors affecting students' performance: a case of private colleges. Bangladesh e-Journal of Sociology, 3 (1): 1-10. https://www.researchgate.net/publication/281060722.

[10] American Library Association. Presidential Committee on Information Literacy: Final report (1989). http://www.ala.org/ala/acrl/acrlpubs/whitepapers/presidential.cfm.

[11] Alagu, A., and Thanuskodi, S. (2018). Assessment of information literacy skills among students of Alagappa University, India. Library Philosophy and Practice (e-journal), 2083. http://digitalcommons.unl.edu/libphilprac/2083.

[12] Yager, Z., Salisbury, F., and Kirkman, L. (2013). Assessment of information literacy skills among first year students. The International Journal of the First Year in Higher Education, 4 (1). 59-71. 10.5204/intjfyhe.v4i1.140.

[13] Malanga, D. F. M. (2017). Assessing information literacy skills: a survey of undergraduate education students at the University of Livingstonia in Malawi. Library Philosophy and $\begin{array}{ll}\text { Practice } & \\ & \text { (e-journal), }\end{array}$ https://digitalcommons.unl.edu/libphilprac/1806.

[14] Kousar, M. and Mahmood, K. (2013). Information literacy skills assessment of undergraduate engineering students. communications in computer and information science book series (CCIS). 397: 471-477.

https://link.springer.com/chapter/10.1007/978-3-319039190_63.

[15] Hossain, M. M., Islam, M. J., Biswas, B. and Hossain, M. K. (2017). The impact of students "socio-economic condition on academic performance in public and national university of Bangladesh. Asian Research Journal of Mathematics, 7 (3): 116. 10.9734/ARJOM/2017/37650.

[16] Shahiduzzaman, M., Ali, M. K. and Islam, M. R. (2017). Factors influencing the academic performance of undergraduate students of private universities in Bangladesh: Modeling Approach. International Journal of Anthropology, 32 (1-2): 10.14673/HE2017121028.

[17] Hossain. S. (2013). A study of determining the relationship between academic achievement and problem behavior of urban secondary school students in Bangladesh. The International Journal of Social Sciences, 8 (1): 1-10. https://www.tijoss.com/8th\%20Volume/saira.pdf

[18] Ahmed, O. and Khanam, M. (2015). Strategies for learning and academic achievement of secondary school students. Dhaka University Journal of Biological Science, 24 (1): 91-97. http://journal.library.du.ac.bd/index.php?journal=dujbs\&page $=$ article\&op=viewFile\&path []$=1015 \&$ path []$=973$.

[19] Alam, M. M., Billah, M. A. and Alam, M. S. (2014). Factors affecting academic performance of undergraduate students at International Islamic University Chittagong (IIUC), Bangladesh. Journal of Education and Practice, 5 (39): 143-154. https://www.iiste.org/Journals/index.php/JEP/article/viewFile/1 $8568 / 19198$.

[20] Danyial, M., Nawaz, T., Aleem, M. and Hassan, A. (2011). The factors affecting the students' performance: a case study of Islamia University of Bahawalpur, Pakistan. African Journal of Education and Technology, 1 (2): 45-51. https://www.academia.edu/23148013/The_Factors_affecting_t he_students_performance_A_case_study_of_The_Islamia_Un iversity_of_Bahawalpur_Pakistan. 
[21] Bhattacharya, R. and Bhattacharya, D. B. (2015). Psychological factors affecting students' academic performance in higher education among students. International Journal for Research and Development in Technology, $\quad 4 \quad$ (1): 63-71. https://www.academia.edu/14692223/Psycho_logical_factorsa ffecting_students_academic_performance_in_higher_educatio n_among_students.

[22] Jabber, M., Aziz, M.A and Zeb, S. (2011). A study on effect of demographic factors on the achievement of secondary school students on the Punjab, Pakistan, International Journal of Academic Research in Business and Social Sciences, 1 (1): 1-13. http://hrmars.com/admin/pics/13.pdf.
[23] Raychaudhuri, A., Debnath, M., Sen, S. and Majumder. (2010). Factors affecting students' academic performance: a case study in Agartala municipal council area. Bangladesh eJournal of Sociology, 7 (2): 34-41. http://bangladeshsociology.org/BEJS\%207.2\%20\%20Factors $\% 20$ Affecting $\% 20$ Students.pdf.

[24] Kumar, B., Hossain, M. E. and Osmani, M. A. G. (2018). Utilization of international remittances in Bangladesh. Remittances Review, 3 (1): 5-18. https://journal.tplondon.com/index.php/rem/article/view/986. 